\title{
Barriers to the effective treatment and prevention of malaria in Africa: A systematic review of qualitative studies David M Maslove ${ }^{1,4}$, Anisa Mnyusiwalla1,4, Edward J Mills, 2,3,4, Jessie McGowan ${ }^{3,4}$, Amir Attaran ${ }^{3,4}$ and Kumanan Wilson*1,4
}

Address: ${ }^{1}$ Department of Medicine, University of Toronto, Toronto, Ontario, Canada, ${ }^{2}$ Faculty of Health Sciences, Simon Fraser University, Vancouver, Canada, ${ }^{3}$ Faculty of Health Sciences, University of Ottawa, Ontario, Canada and ${ }^{4}$ Institute for Population Health, University of Ottawa, Ontario, Canada

Email: David M Maslove - dmaslove@stanford.edu; Anisa Mnyusiwalla - anisa.m@gmail.com; Edward J Mills - emills@sfu.ca; Jessie McGowan - jmcgowan@uottawa.ca; Amir Attaran - aattaran@uottawa.ca; Kumanan Wilson* - kwilson@ohri.ca

* Corresponding author

Published: 25 October 2009

BMC International Health and Human Rights 2009, 9:26 doi:10.1 186/1472-698X-9-26

This article is available from: http://www.biomedcentral.com/1472-698X/9/26

(c) 2009 Maslove et al; licensee BioMed Central Ltd.

This is an Open Access article distributed under the terms of the Creative Commons Attribution License (http://creativecommons.org/licenses/by/2.0), which permits unrestricted use, distribution, and reproduction in any medium, provided the original work is properly cited.
Received: 18 February 2009

Accepted: 25 October 2009

\begin{abstract}
Background: In Africa, an estimated 300-500 million cases of malaria occur each year resulting in approximately I million deaths. More than $90 \%$ of these are in children under 5 years of age. To identify commonly held beliefs about malaria that might present barriers to its successful treatment and prevention, we conducted a systematic review of qualitative studies examining beliefs and practices concerning malaria in sub-Saharan African countries.
\end{abstract}

Methods: We searched Medline and Scopus (1966-2009) and identified 39 studies that employed qualitative methods (focus groups and interviews) to examine the knowledge, attitudes, and practices of people living in African countries where malaria is endemic. Data were extracted relating to study characteristics, and themes pertaining to barriers to malaria treatment and prevention.

Results: The majority of studies were conducted in rural areas, and focused mostly or entirely on children. Major barriers to prevention reported included a lack of understanding of the cause and transmission of malaria (29/39), the belief that malaria cannot be prevented (7/39), and the use of ineffective prevention measures (12/39). Thirty-seven of 39 articles identified barriers to malaria treatment, including concerns about the safety and efficacy of conventional medicines (15/39), logistical obstacles, and reliance on traditional remedies. Specific barriers to the treatment of childhood malaria identified included the belief that a child with convulsions could die if given an injection or taken to hospital (10/39).

Conclusion: These findings suggest that large-scale malaria prevention and treatment programs must account for the social and cultural contexts in which they are deployed. Further quantitative research should be undertaken to more precisely measure the impact of the themes uncovered by this exploratory analysis. 


\section{Background}

Each year, malaria accounts for up to 1 million deaths worldwide, mostly in children under five [1]. In 2002, there were as many as 500 million episodes of clinical Plasmodium falciparum malaria infection, and more than two thirds of these cases were in Africa [2]. More recently, malaria related morbidity and mortality have been significantly worsened by the emergence of widespread drugresistance [3].

During the past decade, numerous large-scale initiatives have been undertaken with the goal of reducing or eradicating the burden of malaria in the developing world. These include among others the Global Fund for AIDS, Tuberculosis, and Malaria (GFATM), the Roll Back Malaria Partnership (RBM), and the Medicines for Malaria Venture (MMV). The ambitious goals set by these programs for reducing the burden of malaria in the near future appear unlikely to be met [4].

The success of antimalarial interventions requires appropriate coordination of efforts, as well as acceptance at the community and individual levels. Numerous barriers to adequate malaria control programs now exist, including the increasing prevalence of drug and insecticide resistance, the high rate of HIV co-infection, climate change, and civil unrest [5]. Added to these are the potential barriers posed by the local cultural contexts in which those at risk of malaria live. Previous experience from the field of HIV/AIDS has shown that local perceptions of this disease and its causative agent are strongly influenced by cultural beliefs, and that these perceptions must be considered in the development of prevention and treatment programs $[6,7]$. Cultural beliefs are likely to similarly influence the treatment and prevention of malaria in Africa. Accounting for these should enhance the efficacy and scope of malaria control programs. To our knowledge, no study has systematically compiled the results of qualitative research on cultural beliefs about malaria in sub-Saharan Africa, across a range of age groups and countries.

Qualitative studies provide greater insights into personal experiences than quantitative methods [8]. An excellent review of qualitative studies done between 1996 and 2000 explored qualitative data "pertaining to the home management of illness episodes of malaria in sub-Saharan Africa" [9]. This study updates the results of that study, uses formal systematic review methods for qualitative studies, and does not restrict the analysis to home management of episodes.

\section{Methods}

We conducted a systematic review of qualitative studies using methods previously described [10]. We identified articles from a literature search, and systematically extracted relevant themes identified in each article. These themes formed the basis of a checklist used to determine the frequency with which each theme had been identified in each of the papers.

\section{Search Strategy}

To identify articles for inclusion in our analysis, we searched Medline (1966 to June, 2009) and Scopus (1968 to June, 2009). The complete search strategy is outlined in the Appendix. Reports produced by government, nongovernmental organizations, and industry that were not subject to peer review, so-called "grey literature", were not included because the methodological quality of such accounts is difficult to ascertain.

\section{Selection of abstracts}

Two of us (AM, DM) independently screened a representative sample of 250 articles, in order to develop inclusion and exclusion criteria. The primary author then screened the remaining articles, using the criteria developed. We retrieved all the articles describing studies that made any use of qualitative methods (semi-structured, structured or unstructured interviews, or focus group discussions) to investigate the knowledge, beliefs, attitudes, and practices related to malaria amongst residents of an area where malaria is prevalent. Where no abstract was available, we retrieved articles if they included the term "malaria" in the title, with at least one of "beliefs", "knowledge", "attitudes", or "practice". We added to these the papers that were identified through a review of references.

To ensure we included purely observational qualitative data representing the views of the majority of patients and caregivers, we examined in detail the methods sections of all of the articles selected from the review of abstracts. We excluded the remaining quantitative studies, the second instances of articles found in both databases, those in which an experimental or interventional design was used, and those focused on either travellers, drug sellers, adverse drug events, or malaria in pregnancy. Of the remaining articles, we selected only those written in English, describing studies conducted in sub-Saharan African countries.

\section{Extraction of themes}

Two of us (AM, DM) independently reviewed the results sections of a representative sample of the articles selected for analysis, and extracted themes relating to beliefs about the causes, treatment, and prevention of malaria. A separate author (KW) categorized the extracted themes to produce a scoring checklist. With this checklist, all of the included articles were reviewed, to determine which articles identified each of the themes. Discrepancies were resolved by consensus. 
For studies carried out amongst a population where there is no direct translation of the term "malaria", the local terminology for febrile illness was assumed to refer to malaria. This assumption was only made in cases in which the original authors indicated that this was warranted, and in which they themselves had used the terms interchangeably. For articles in which both qualitative and quantitative data were reported, only the qualitative data were used in the analysis.

For a representative sample of articles, we also extracted data on study methodology and assessed quality by means of the CASP critical appraisal tool [11]. As the outcome of this appraisal did not affect our study inclusion criteria, or the weighting of their findings in our analysis, the results are not reported in detail here.

\section{Statistical analysis}

For the initial selection of abstracts, we estimated level of agreement between reviewers using the $\kappa$ statistic.

\section{Results}

\section{Study selection and characteristics}

Our search identified 1017 articles (See Figure 1), and the review of references identified an additional 17 articles. Of these, 869 were excluded based on the review of abstracts. The $\kappa$ statistic for the initial selection was 0.77 , indicating excellent agreement. Of the remaining 165 studies, a further 126 were excluded by consensus because they used only quantitative methodologies, were conducted in non-African locales, or pertained to either travellers or pregnant women. A total of 39 articles were included in the analysis [12-50].

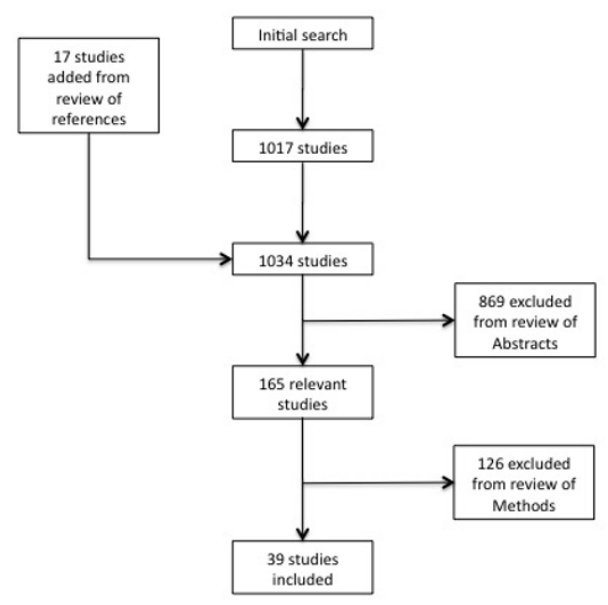

Figure I

Flow diagram of the studies used in the analysis.
The characteristics of the studies selected are shown in Tables 1 and 2. The studies were done in 12 different countries, with the majority conducted in either East Africa (Kenya, Tanzania, Uganda - 18 studies), or West Africa (Benin, Burkina Faso, Côte d'Ivoire, Ghana, Nigeria - 13 studies). The others were conducted in Southern Africa (Malawi, Zambia - 5 studies), Ethiopia (2 studies), and Sudan (1 study). The articles were published between the years 1992 and 2008, with a median year of publication of 2002. Four of the 39 included articles primarily focused on adults, 19 articles primarily focused on children, and 16 articles were of mixed focus. Twenty-five studies took place amongst rural or semi-rural populations, 11 were conducted in both rural and urban settings, and 3 were limited to urban areas alone. Twenty-seven of the 39 studies included as respondents the caregivers of young children. Other groups studied included non-caregiver adults, health workers, traditional healers, community leaders, and school-aged children. Qualitative data were obtained mostly by means of focus group discussions and interviews.

\section{Local terminology for febrile illnesses}

In many of the studies included in the analysis, the local vernacular of disease terms was used. While these languages often lacked a direct translation for the English word "malaria", they included a single-word term or phrase of similar meaning. Examples of this include the terms asra (Ghana), homa (Tanzania and Kenya), soumaya (Burkina Faso), and omusujja (Uganda). While these terms translate roughly to the English word "fever", their meanings encompass a number of other symptoms, such that they correspond closely to the clinical presentation of malaria $[13,31]$.

\section{Barriers to Prevention}

The themes extracted from the articles are shown in Tables 3 and 4 [see additional file 1 and 2]. Twenty-nine of the 39 articles included identified potential barriers to effective malaria prevention. Numerous barriers to the use of bednets were identified, including cost, and ease of use. As a respondent from a study in Ghana explained, "The problem associated with a bednet is that you sweat a lot when sleeping under it. I don't know the price now but I think only a few people can afford it" [15]. Concerns about repellents reported in one article included unpleasant side effects from coil smoke and insecticide sprays [48].

Twelve articles reported the use of ineffective prevention practices, such as eating a balanced diet, drinking herbal teas, wearing charms or amulets, and vaccinating children. Seven articles identified the belief that malaria cannot be prevented. 
Table I: Characteristics of qualitative studies in children

\begin{tabular}{|c|c|c|c|c|c|c|}
\hline Name & Year & Country & Setting & Population & Primary methods (n) & Disease terminology \\
\hline Mwenesi & 1995 & Kenya & Peri-urban, urban, rural & $\begin{array}{l}\text { Mothers with ill children } \\
\text { Adults }\end{array}$ & $\begin{array}{l}\text { Interviews } \\
\text { Key informant interviews }\end{array}$ & homa \\
\hline Mwenesi & 1995 & Kenya & $\begin{array}{l}\text { Urban township, slum, } \\
\text { rural }\end{array}$ & People in the community & $\begin{array}{l}\text { Key informant interviews } \\
(60)\end{array}$ & Malaria, homa, dege \\
\hline Makemba & 1996 & Tanzania & Rural & $\begin{array}{l}\text { Traditional healers } \\
\text { Parents who had taken their } \\
\text { children to healers }\end{array}$ & $\begin{array}{l}14 \text { interviews } \\
3 \text { focus groups }\end{array}$ & Degedege, homa ya kawaida \\
\hline Ahorlu & 1997 & Ghana & Rural & Caregivers of children under 10 & 8 focus groups (1057) & Asra, asraku, atridi \\
\hline Williams & 1999 & Zambia & Rural & $\begin{array}{l}\text { Mothers of children under } 5 \\
\text { Father of children under } 5 \\
\text { Others* }\end{array}$ & $\begin{array}{l}9 \text { focus groups } \\
7 \text { focus groups } \\
36 \text { in-depth interviews }\end{array}$ & $\begin{array}{l}\text { thupi kuphya, malungo, cilunguzi, } \\
\text { malaria, cinthu, cawoka, malaria, } \\
\text { yakulu, 'big malaria' }\end{array}$ \\
\hline Baume & 2000 & Zambia & Rural and urban & $\begin{array}{l}\text { Caregivers of children under } 5 \\
\text { with recent febrile illness }\end{array}$ & $\begin{array}{l}\text { Semi-structured interviews } \\
\text { (I54) }\end{array}$ & - \\
\hline Muela & 2002 & Tanzania & Rural and urban & Mothers of children under 5 & $\begin{array}{l}\text { In-depth }(8 I) \text { and follow-up } \\
(10) \text { interviews }\end{array}$ & $\begin{array}{l}\text { Malaria, homa, homa ya mbu, } \\
\text { homa kali, degedege, malaria ya } \\
\text { kichwa }\end{array}$ \\
\hline Comoro & 2003 & Tanzania & Urban, peri-urban, rural & $\begin{array}{l}\text { Mothers of sick children under } \\
5, \text { Health workers }\end{array}$ & $\begin{array}{l}10 \text { focus groups ( } 85) \\
6 \text { focus groups }(43)\end{array}$ & Homa ya malaria, degedege \\
\hline Muula & 2004 & Malawi & Peri-urban & $\begin{array}{l}\text { Primary school pupils aged I2- } \\
18\end{array}$ & 4 focus groups ( 40 ) & - \\
\hline Nsungwa-Sabiiti & 2004 & Uganda & Rural & Mothers, fathers, grandparents & 10 focus groups & omutsutsa \\
\hline Akogun & 2005 & Nigeria & Rural & Mothers & 6 focus groups & zazzabi \\
\hline Kaona & 2005 & Zambia & Rural & $\begin{array}{l}\text { Mothers, fathers, grandparents, } \\
\text { health care providers, } \\
\text { community members }\end{array}$ & $\begin{array}{l}12 \text { focus groups (97), } 29 \\
\text { key informant interviews }\end{array}$ & $\begin{array}{l}\text { malaria, inzekema, impepo, sinsa, } \\
\text { ichinzekema }\end{array}$ \\
\hline Falade & 2006 & Nigeria & Urban and rural & $\begin{array}{l}\text { Mothers, fathers, and } \\
\text { caregivers of children under } 10\end{array}$ & Focus groups & Iba, iba lasan \\
\hline Kamat & 2006 & Tanzania & Rural & Mothers/caretakers & In-depth interviews (45) & $\begin{array}{l}\text { Homa ya kawaida, homa kali, } \\
\text { homa ya malaria, degedege }\end{array}$ \\
\hline Makundi & 2006 & Tanzania & Rural & $\begin{array}{l}\text { Mothers/caregivers } \\
\text { Traditional healers }\end{array}$ & $\begin{array}{l}2 \text { Focus groups } \\
\text { In-depth interviews }\end{array}$ & $\begin{array}{l}\text { Malaria ya kawaida, malaria kali, } \\
\text { degedege }\end{array}$ \\
\hline Malik & 2006 & Sudan & Rural & Mothers & 10 Focus groups & - \\
\hline Montgomery & 2006 & Tanzania & Urban and rural & $\begin{array}{l}\text { Parents/caretakers of children } \\
\text { under } 5 \\
\text { Health practitioners }\end{array}$ & $\begin{array}{l}\text { Interviews (79) } \\
\text { Interviews (55) }\end{array}$ & - \\
\hline Beiersmann & 2007 & Burkina Faso & Rural & $\begin{array}{l}\text { Mothers } \\
\text { Guérisseurs, nurses, traditional } \\
\text { birth attendants }\end{array}$ & $\begin{array}{l}\text { I7 Focus groups } \\
\text { Semi-structured interviews } \\
\text { (I7) }\end{array}$ & Sumaya, dusukun kono \\
\hline Deressa & 2007 & Ethiopia & Rural & $\begin{array}{l}\text { Mothers of children under } 5 \\
\text { Fathers of children under } 5\end{array}$ & $\begin{array}{l}3 \text { Focus groups } \\
3 \text { Focus groups }\end{array}$ & busa \\
\hline
\end{tabular}

\footnotetext{
* Parents, drug vendors, traditional healers, and community- and facility-based health workers
} 
Twenty-seven out of the 39 articles analyzed described the belief that malaria is caused by factors other than mosquitoes and Plasmodium parasites (median publication year 2002). Of these, the most frequently identified included environmental factors (excessive heat, wind, or cold), dietary factors (eating oily foods, certain fruits and grains, or too much of the same foods), drinking or bathing in dirty water, and supernatural causes (witchcraft, sorcery, and possession by spirits).

In 6 articles, mosquitoes were not mentioned amongst the causes of malaria reported by the study participants. These beliefs were shown in some studies to have an important impact on prevention:

Malaria cannot be prevented because we were all born with it and it grows in us once a while, it manifests itself by giving us fever. When we treat it, we get better but the malaria is still there and will come again but to prevent it from coming you have to take an enema every day [15].

A related theme that was identified in 19 of the articles was the tendency to ascribe syndromes that likely represent severe or complicated malaria, including convulsions and anemia, to non-malarial causes (median publication year 2002). Specifically, convulsions were frequently ascribed to witchcraft, possession by spirits, or exposure to birds and animals with supernatural properties. This theme was identified most frequently in articles focused on malaria in children.

\section{Barriers to Treatment}

Thirty-seven of the 39 articles identified barriers to active treatment. The most frequently identified concern about conventional therapy, reported in 10 of the articles analyzed, was the belief that a child with convulsions could die if given an injection. Three of these articles also identified the belief that a sick child could die if taken to hospital. Yet another article reported the belief that antimalarials should be withheld from a child with fits. Nearly all of the studies that identified these themes were conducted in East Africa (median publication year 2000).

Other reported barriers to treatment included beliefs about the efficacy and use of conventional medicines, and beliefs about the role of traditional therapies. A total of 17 articles described a preference for traditional remedies in cases where the illness was believed to be caused by spirits or witchcraft, when complications occurred, or as a means of removing the root cause prior to supportive care in hospital. This was particularly evident in the case of childhood convulsions, which were often believed to be due to spirits or witchcraft, and were accordingly treated by traditional means:
"Degedege is caused by bad spirits. In this realization, spirits that cause convulsion must be removed first so that Western and other medication can work in treating the child. That is why we start at the traditional healer for treatment of a convulsed child and later we take him or her to hospital" [32].

Failure of hospital treatment was identified in 2 studies as an indication that the illness was due to witchcraft. Three studies reported beliefs that the taste and colour of pills was a reflection of their efficacy, specifically that bitter medications such as chloroquine were more effective.

We identified numerous behavioural and pragmatic barriers to the use of conventional medicines. Barriers reported about use of treatment facilities included distance from the facility, perceived quality of treatment provided, and fear of scolding from clinic staff:

During the time the child was sick, I was also sick. The other thing is that it is very far to the health center. Unless I had a bicycle, I could not have taken her there.

...And those people at the clinic never really examine our children. They just write what we tell them. If you ask questions, they just shout at you... [17].

The prohibitive cost of treatment was described in 12 articles. Six articles identified the practice of stopping medications once symptoms had ceased, often as a means of rationing pills to preserve a supply for future illness episodes:

...sometimes just after administering two times you find the child recovers, starts playing. So you stop and keep the medicine, in case the child falls ill again [17].

A total of 23 articles described conventional medicines and health care clinics as second line treatment options. Nearly all of the articles described the use of traditional healing methods, including consultation with traditional healers, use of herbal remedies, sponging and bathing, and various forms of fumigation. These methods were often described as first line treatment for malaria, before conventional treatments are employed:

Usually patients are first given herbs especially mululuza (a popular herb used for omusujja) then they go on to tablets from shops and eventually they take the patients to the hospital, especially if the omusujja fails to respond to the herbs/tablets [30].

\section{Discussion}

We systematically reviewed qualitative studies examining the local understanding of malaria in sub-Saharan African 
Table 2: Characteristics of qualitative studies in adults and mixed populations

\begin{tabular}{|c|c|c|c|c|c|c|}
\hline Name & Year & Country & Setting & Population & Primary methods (n) & Disease terminology \\
\hline \multicolumn{7}{|c|}{ Adult focus } \\
\hline Agyepong & 1992 & Ghana & Rural & $\begin{array}{l}\text { Men and women over } 20 \text { years } \\
\text { old }\end{array}$ & 6 focus groups & Asra, asraku \\
\hline Stevens & 1995 & Tanzania & Urban, peri-urban & Adults, community leaders & $\begin{array}{l}8 \text { focus groups ( } 94) \text {, } \\
72 \text { focused discussions (175) }\end{array}$ & malaria \\
\hline Rashed & 1999 & Benin & Rural & $\begin{array}{l}\text { Parents, community elders, } \\
\text { non-western healers, health } \\
\text { care providers }\end{array}$ & $\begin{array}{l}23 \text { focus groups ( } 252), 8 \text { semi- } \\
\text { structured interviews }\end{array}$ & Ouevozon \\
\hline Nyamongo & 2002 & Kenya & Rural & Adults aged 18 to 80 & Interviews (35) & - \\
\hline \multicolumn{7}{|c|}{ Mixed focus } \\
\hline Helitzer-Allen & 1993 & Malawi & Rural & $\begin{array}{l}\text { Mothers, pregnant women, } \\
\text { husbands, health workers, } \\
\text { community leaders }\end{array}$ & $\begin{array}{l}160 \text { in-depth interviews }{ }^{\dagger} \\
24 \text { focus groups }{ }^{\dagger}\end{array}$ & Malungo \\
\hline Agyepong & 1994 & Ghana & Rural and urban & $\begin{array}{l}\text { Caregivers of children under } 5 \\
\text { years }\end{array}$ & Interviews (47I) & Asra, asraku \\
\hline Kengeya-Kayondo & 1994 & Uganda & Rural & $\begin{array}{l}\text { Women, mothers, female } \\
\text { caregivers }\end{array}$ & $\begin{array}{l}5 \text { focus groups ( } 42), 395 \text { semi- } \\
\text { structured interviews, } 64 \\
\text { key informant interviews }\end{array}$ & - \\
\hline Winch & 1996 & Tanzania & Rural & $\begin{array}{l}\text { Group meetings with local } \\
\text { government officials, religious } \\
\text { leaders, teachers, and health } \\
\text { workers, }\end{array}$ & $\begin{array}{l}40 \text { unstructured interviews } \\
\text { and focus groups, pile sorting } \\
\text { with } 8 \text { respondents }\end{array}$ & $\begin{array}{l}\text { Homa, homa kali, homa ya } \\
\text { kuchemka, homa ya malaria, } \\
\text { degedege }\end{array}$ \\
\hline Muela & 1998 & Tanzania & Semi-rural & $\begin{array}{l}\text { Adult malaria patients, } \\
\text { caretakers of children under } 5 \text {, } \\
\text { mothers, villagers, traditional } \\
\text { healers }\end{array}$ & $\begin{array}{l}6 \text { focus groups, } 103 \\
\text { interviews }\end{array}$ & $\begin{array}{l}\text { Malaria, homa, homa ya } \\
\text { malaria, degedege }\end{array}$ \\
\hline Munguti & 1998 & Kenya & Rural & $\begin{array}{l}\text { Heads of households reporting } \\
\text { a case of malaria within the } \\
\text { previous } 2 \text { weeks }\end{array}$ & Structured interviews (463) & - \\
\hline \multicolumn{7}{|c|}{ Mixed focus (cont'd) } \\
\hline Oberlander & 2000 & Tanzania & Rural village & - & $\begin{array}{l}\text { Participant observation, } \\
\text { informal group discussion, } \\
\text { ethnographic interviews }\end{array}$ & $\begin{array}{l}\text { Degedege, mchango, } \\
\text { kibwengo, malaria }\end{array}$ \\
\hline Brieger & 2001 & Nigeria & Urban & Adults, child caregivers & $\begin{array}{l}36 \text { focus groups, } 154 \\
\text { interviews }\end{array}$ & $\begin{array}{l}\text { Iba, malaria, fever, malaria } \\
\text { fever }\end{array}$ \\
\hline Nuwaha & 2002 & Uganda & Rural, partly-urban & $\begin{array}{l}\text { Men, women, heads of } \\
\text { households }\end{array}$ & 4 focus groups & omushwija, omussuja \\
\hline Okrah & 2002 & Burkina Faso & Rural, partly-urban & $\begin{array}{l}\text { Caregivers of children under } 5 \text {, } \\
\text { adult community members }\end{array}$ & $\begin{array}{l}10 \text { focus groups, } 9 \text { key } \\
\text { informant interviews }\end{array}$ & Soumaya \\
\hline Adongo & 2005 & Ghana & Rural & $\begin{array}{l}\text { Women, men, couples, } \\
\text { mothers, healers, bednet } \\
\text { vendors }\end{array}$ & 8 focus groups, 98 interviews & Pua, feber, nienga, zumzuri \\
\hline Eriksen & 2005 & Tanzania & Rural and urban & $\begin{array}{l}\text { Mothers, fathers, health } \\
\text { workers }\end{array}$ & 12 focus groups & - \\
\hline Onwujekwe & 2005 & Nigeria & Rural & Men, women, youths & 9 focus groups & $i b a$ \\
\hline Deressa & 2007 & Ethiopia & Rural & $\begin{array}{l}\text { Mothers of children under } 5 \\
\text { Men with at least one child }\end{array}$ & $\begin{array}{l}3 \text { Focus groups } \\
4 \text { Focus groups }\end{array}$ & busa \\
\hline
\end{tabular}


Table 2: Characteristics of qualitative studies in adults and mixed populations (Continued)

\begin{tabular}{llllll}
\hline Essé & 2008 & Côte d'Ivoire Rural & $\begin{array}{l}\text { School children aged I0-I4 } \\
\text { Health practitioners, health } \\
\text { facility staff, local healers, } \\
\text { religious leaders }\end{array}$ & $\begin{array}{l}\text { 6 Focus groups } \\
\text { I5 Key informant interviews }\end{array}$ & $\begin{array}{c}\text { Djèkouadjo, djékadjo, ewuego, } \\
\text { anum\& }\end{array}$ \\
\hline Idowu & 2008 & Nigeria & Rural & Adults & Focus groups \\
\hline
\end{tabular}

tinterview target groups -- pregnant women, women who had recently given birth, chiefs and village headmen, husbands of pregnant women, traditional birth attendants, health worker, traditional advisors, and traditional healers

ttfocus group target groups -- pregnant women, women who had recently given birth, and husbands of pregnant women

countries, as a means of identifying important beliefs and practices that might pose barriers to effective malaria treatment and prevention. To our knowledge, ours is the first systematic review of qualitative studies in this area. While qualitative methods remain useful in exploratory research and hypothesis generation, their results when taken in isolation are of limited value in making more general claims. Our method addresses this shortcoming by using a content analysis approach to combine the results of many qualitative studies conducted in different settings amongst various populations [10].

Our results have importance for public health planners and local physicians. We found that cultural beliefs regarding the cause of malaria may differ from scientific explanations, and that first-line treatments are frequently based on traditional practices. These findings indicate that public health prevention and treatment campaigns need to include culturally sensitive strategies that provide education in the context of local understanding and beliefs.

The results of our analysis show that while the malariamosquito link is recognized in malaria-endemic regions of sub-Saharan Africa, a number of alternate causative mechanisms are also endorsed. Quantitative data from the studies included in our analysis support this finding, showing that up to $80 \%$ of survey respondents cite causes of malaria that do not implicate transmission by mosquitoes $[12-14,37,45,50]$. Similarly, only $8-27 \%$ of respondents related common complications of malaria such as convulsions and anemia, to mosquitoes or malaria $[12,40]$. This finding has important implications for malaria control programs, which rely heavily on vector control strategies, including the use of insecticide-treated bednets (ITNs). Users must believe in a mosquito-based etiology of malaria to be sufficiently motivated to purchase or otherwise acquire ITNs, and adhere to their use.

Improved understanding of malaria transmission is also likely to result in better adherence to effective prevention strategies. For one example, a study of post-partum women in Tanzania showed that a high level of knowledge of malaria transmission was positively correlated with the use of ITNs [51]. Taken together, these findings along with those from our study, support a role for educa- tion as a key component of any project aiming to reduce the burden of malaria in endemic areas in Africa.

We also identified a number of unproven prevention practices that are potential consequences of the beliefs about causation. Quantitative data from one of the studies included in our analysis showed that while $19 \%$ of mothers believed charms or amulets could prevent convulsions in their children, only $9 \%$ subscribed to mosquito avoidance for this purpose [40]. While most of these practices are likely not to be harmful, they pose a possible threat to successful malaria prevention by supplanting the use of more effective measures. Use of such methods may also foster a false sense of protection amongst those who apply them.

The WHO malaria treatment guidelines currently recommend artemisinin-based combination therapies (ACTs) as first-line treatment for both uncomplicated and severe malaria [52]. Access to ACTs, however, is still limited for many populations, amongst which traditional methods remain the primary source of care. The results of this review indicate that traditional remedies are often used in the treatment of both uncomplicated and severe malaria. Some of these methods, such as tepid sponging for children with high fevers, have demonstrated some benefit in a small number of clinical trials [53]. For the most part, however, their efficacy remains unexamined, and thus uncertain. While certain herbal treatments may be of benefit - artemesinin itself is a derivative of the Chinese plant Artemisia annua - many traditional therapies may be ineffective, or even harmful. Their use as first-line treatment should be countered with the implementation of available and effective antimalarials.

Our analysis also shows that traditional healers are frequently consulted in the treatment of malaria, likely as a consequence of their role within local cultures, and of geographic and financial barriers to accessing treatment from health clinics. Survey data from one study in our analysis indicated that $70 \%$ of mothers sought treatment for febrile children from traditional healers [17]. As such, they are particularly well positioned to affect changes in the treatment and prevention practices of their patients. Local healers should be closely involved in malaria treat- 
ment programs, and should be encouraged to incorporate the use of evidence-based antimalarials into their practice. The reach and influence of traditional healers as primary and first-line caregivers should be utilized in order to improve timely and open access to ACTs.

The results of this review describe significant scepticism around the use of conventional medicines in the treatment of malaria, and in particular in the treatment of severe malaria in children. We identified the concern amongst caregivers of young children that giving an injection to a child with convulsions can be fatal. This belief may in fact be a consequence of local treatment practices, in which seeking hospital care is delayed in deference to traditional treatments. Death following an injection may therefore be a result of the high mortality of late-presenting severe malaria, rather than of the injection itself. Current guidelines continue to support the use of parenteral antimalarials in children with severe malaria, as well as the use of rectal or parenteral benzodiazepines for convulsions whenever this is feasible [52].

We found 6 articles that described the practice of discontinuing malaria treatment once symptoms were seen to resolve, often as a means of rationing medicines for future illness episodes. This finding is particularly worrisome, as poor adherence to treatment is a risk factor for treatment failure [3], and could promote the emergence of drug resistant parasites.

Our study has several strengths and limitations to consider in the interpretation of its findings. We used established systematic review techniques to identify and extract data in an unbiased manner. Using a methodology published elsewhere, we coded and extracted themes, resolving disagreements through $3^{\text {rd }}$ party arbitration or consensus [10]. However, our analysis relied on the assumption that the local terminology for febrile illnesses used in many of the articles referred specifically to malaria. It is possible that these terms in fact describe febrile illnesses other than malaria. In the case of the term degedege, which was assumed to refer to severe malaria or cerebral malaria in children, it is possible that non-malarial causes of febrile convulsions in children (such as meningitis, encephalitis, or high fever alone from any cause) were inadvertently included in our analysis. Our justification for using local terminology in our analysis is twofold. First, the substitution was carried forward only for those studies in which the original authors, with significant exposure to the local language and culture under investigation, also made the substitution. Second, given that the studies included were conducted in malariaendemic stable high-transmission areas, it is likely that malaria accounts for more episodes of fever in these regions than any other cause. Indeed, the current WHO treatment guidelines for malaria recommend empirical antimalarial treatment for children under five with a temperature of $>37.5^{\circ} \mathrm{C}$, as malaria is the most frequent cause of fever in this age group [52].

Other potential limitations are related to the studies included in our analysis. First, it is possible that the search strategy used did not adequately capture the most appropriate studies for inclusion, especially since many of these may have been published in smaller journals and may not have been included in the indexes we searched. Our review of key references was used to mitigate against this possible bias. Second, there were limited data in the included studies by which to assess the rigor of the experimental methods used. The extracted data may therefore be of heterogeneous quality. Nonetheless, consistency of themes was observed amongst the various studies included. Moreover, amongst those studies that did include quantitative data (23/39), these tended to support the findings of the qualitative components. Third, the countries in which the included studies were carried out are themselves a heterogeneous group, with significant cultural and linguistic differences between them. Though consistency of themes from studies in different countries was found, our findings should be interpreted and applied on a case-by-case basis according to the cultural context of a particular region. Finally, while it is likely that the themes identified in this study are important amongst the populations included, little can be gleaned about beliefs that were not reported. Thus, our method is specific, but not sensitive, for the identification of beliefs about malaria amongst the populations studied. Furthermore, the degree to which these findings can be applied more broadly to other populations remains unknown.

\section{Conclusion}

We systematically identified barriers to effective malaria treatment and prevention that are consequences of logistical impediments, scepticism of conventional treatments, preference for traditional modalities, and incomplete understanding of malaria causation and transmission. Our findings from these qualitative studies should be used to formulate questionnaires and other research tools for use in larger quantitative studies, in order to better determine the impact of these important cultural perceptions on the prevention and treatment of malaria in subSaharan Africa. Accounting for the cultural beliefs and practices of sub-Saharan populations at risk of malaria is likely to enhance the effectiveness of large-scale aid programs, and ensure that the financial and logistical resources being committed to combat malaria are being appropriately allotted.

\section{Competing interests}

The authors declare that they have no competing interests. 


\section{Authors' contributions}

DM contributed to the conception and design of the study, acquisition, analysis, and interpretation of data, and drafting and revision of the manuscript. AM contributed to the conception of the study, and the acquisition and analysis of data. EJM contributed to the conception and design of the study, interpretation of data, and revision of the manuscript. JM contributed to the acquisition of the data. AA contributed to the conception of the study and interpretation of data. KW contributed to the conception and design of the study, analysis and interpretation of data, and revisions of the manuscript. All authors read and approved the final manuscript.

\section{Appendix \\ Search Strategy}

We searched both Medline and Scopus from 1996 to May, 2009, using MeSH terms and textwords for "malaria", and combined these with MeSH and textwords terms for "National Health Programs", "communicable disease control" and "referral and consultation." This set of results was further focused by combining its results with MeSH terms for "health knowledge, attitudes, Practice" and "cultural characteristics" and textwords for "attitudes" and "beliefs". To mitigate any potential publication bias, we also reviewed the references of key papers.

\section{Additional material}

\section{Additional file 1}

Themes identified from articles focused on children. Table shows the themes extracted from articles focused on children.

Click here for file

[http://www.biomedcentral.com/content/supplementary/1472698X-9-26-S1.pdf]

\section{Additional file 2}

Themes identified from articles focused on adults, and with mixed focus. Table shows the themes extracted from articles focused on adults, and with mixed focus.

Click here for file

[http://www.biomedcentral.com/content/supplementary/1472698X-9-26-S2.pdf]

\section{Acknowledgements}

The authors wish to thank Risa Shorr for her significant contribution to the design and execution of the literature search strategy.

\section{References}

I. Breman JG, Alilio MS, Mills A: Conquering the intolerable burden of malaria: what's new, what's needed: a summary. $\mathrm{Am} J$ Trop Med Hyg 2004, 7 I:I-I 5.

2. Snow RW, Guerra CA, Noor AM, Myint HY, Hay SI: The global distribution of clinical episodes of Plasmodium falciparum malaria. Nature 2005, 434:2। 4-7.

3. Baird JK: Effectiveness of antimalarial drugs. N Engl J Med 2005, 352:1565-77.
4. Attaran A, Barnes KI, Curtis C, d'Alessandro U, Fanello Cl, Galinski MR, Kokwaro G, Looareesuwan S, Makanga M, Mutabingwa TK, Talisuna A, Trape JF, Watkins WM: WHO, the Global Fund, and medical malpractice in malaria treatment. Lancet 2004, 363:237-40.

5. Greenwood BM, Bojang K, Whitty CJ, Targett GA: Malaria. Lancet 2005, 365: |487-98.

6. Nicoll A, Laukamm-Josten U, Mwizarubi B, Mayala C, Mkuye M, Nyembela G, Grosskurth H: Lay health beliefs concerning HIV and AIDS--a barrier for control programmes. AIDS Care 1993, 5:23I-4I.

7. Boer $\mathrm{H}$, Emons PA: Accurate and inaccurate HIV transmission beliefs, stigmatizing and HIV protection motivation in northern Thailand. AIDS Care 2004, I 6:167-76.

8. Mills EJ, Montori VM, Ross CP, Shea B, Wilson K, Guyatt GH: Systematically reviewing qualitative studies complements survey design: an exploratory study of barriers to paediatric immunisations. J Clin Epidemiol 2005, 58: I I 0 I-8.

9. Williams HA, Jones CO: A critical review of behavioral issues related to malaria control in sub-Saharan Africa: what contributions have social scientists made? Soc Sci Med 2004, 59:501-23.

10. Mills E, Jadad AR, Ross C, Wilson K: Systematic review of qualitative studies exploring parental beliefs and attitudes toward childhood vaccination identifies common barriers to vaccination. J Clin Epidemiol 2005, 58: I08I-8.

II. Critical Appraisal Skills Program (CASP): 10 questions to help you make sense of qualitative research. 2003 [http:// www.phru.nhs.uk/pages/PHD/resources.htm]. Oxford: CASP

12. Adongo PB, Kirkwood B, Kendall C: How local community knowledge about malaria affects insecticide-treated net use in northern Ghana. Trop Med Int Health 2005, 10:366-78.

13. Agyepong IA: Malaria: ethnomedical perceptions and practice in an Adangbe farming community and implications for control. Soc Sci Med 1992, 35:131-7.

14. Agyepong IA, Manderson L: The diagnosis and management of fever at household level in the Greater Accra Region, Ghana. Acta Trop 1994, 58:317-30.

15. Ahorlu CK, Dunyo SK, Afari EA, Koram KA, Nkrumah FK: Malariarelated beliefs and behaviour in southern Ghana: implications for treatment, prevention and control. Trop Med Int Health 1997, 2:488-99.

16. Akogun $\mathrm{OB}$, John KK: Illness-related practices for the management of childhood malaria among the Bwatiye people of north-eastern Nigeria. Malar J 2005, 4: I3.

17. Baume C, Helitzer D, Kachur SP: Patterns of care for childhood malaria in Zambia. Soc Sci Med 2000, 5 I: | 49 |-503.

18. Beiersmann C, Sanou A, Wladarsch E, De Allegri M, Kouyaté B, Müller O: Malaria in rural Burkina Faso: local illness concenpts, patterns of traditional treatment and influence on health-seeling behaviour. Malar J 2007, 6:106.

19. Brieger WR, Sesay HR, Adesina H, Mosanya ME, Ogunlade PB, Ayodele JO, Orisasona SA: Urban malaria treatment behaviour in the context of low levels of malaria transmission in Lagos, Nigeria. Afr J Med Med Sci 200I, 30(Suppl):7-I5.

20. Comoro C, Nsimba SE, Warsame M, Tomson G: Local understanding, perceptions and reported practices of mothers/ guardians and health workers on childhood malaria in a Tanzanian district--implications for malaria control. Acta Trop 2003, 87:305-I3.

21. Deressa W, Ali A, Berhane Y: Maternal responses to childhood febrile illnesses in an area of seasonal malaria transmission in rural Ethiopia. Acta Trop 2007, I02:1-9.

22. Deressa W, Ali A, Hailemariam D: Malaria-related health-seeking behaviour and challenges for care providers in rural Ethiopia: Implications for control. J Biosoc Sci 2008, 40: I I 5-35.

23. Eriksen J, Nsimba SE, Minzi OM, Sanga AJ, Petzold M, Gustafsson LL, Warsame MY, Tomson G: Adoption of the new antimalarial drug policy in Tanzania--a cross-sectional study in the community. Trop Med Int Health 2005, I 0:1038-46.

24. Essé C, Utzinger J, Tschannen AB, Raso G, Pfeiffer C, Granado S, Koudou BG, N'Goran EK, Cissé G, Girardin O, Tanner M, Obrist B: Social and cultural aspects of 'malaria' and its control in central Côte d'Ivoire. Malar J 2008, 7:224.

25. Falade CO, Ogundiran MO, Bolaji MO, Ajayi IO, Akinboye DO, Oladepo O, Adeniyi JD, Oduola AMJ: The influence of cultural 
perception of causation, complications, and severity of childhood malaria on determinants of treatment and preventive pathways. Int $Q$ Community Health Educ 2006, 24:2005-347.

26. Helitzer-Allen D, Kendall C, Wirima J]: The role of ethnographic research in malaria control: An example from Malawi. Research in the Sociology of Health Care 1993, 10:269-86.

27. Idowu OA, Mafiana CF, Luwoye IJ, Adehanloye O: Perceptions and home management practices of malaria in some rural communities in Abeokuta, Nigeria. Travel Med Infect Dis 2008, 6:210-214.

28. Kamat VR: "I thought it was only ordinary fever!": cultural knowledge and the micropolitics of therapy seeking for childhood febrile illness in Tanzania. Soc Sci Med 2006, 62:2945-2959.

29. Kaona FA, Tuba M: A qualitative study to identify community structures for management of severe malaria: a basis for introducing rectal artesunate in the under five years children in Nakonde District of Zambia. BMC Public Health 2005, 5:28.

30. Kengeya-Kayondo JF, Seeley JA, Kajura-Bajenja E, Kabunga E, Mubiru E, Sembajja F, Mulder DW: Recognition, treatment seeking behaviour and perception of cause of malaria among rural women in Uganda. Acta Trop 1994, 58:267-73.

31. Makemba AM, Winch PJ, Makame VM, Mehl GL, Premji Z, Minjas JN, Shiff Cl: Treatment practices for degedege, a locally recognized febrile illness, and implications for strategies to decrease mortality from severe malaria in Bagamoyo District, Tanzania. Trop Med Int Health 1996, I:305-I3.

32. Makundi EA, Malebo HM, Mhame P, Kitua AY, Warsame M: Role of traditional healers in the management of severe malaria among children below five years of age: the case of Kilosa and Handeni Districts, Tanzania. Malar J 2006, 5:58.

33. Malik EM, Hanafi K, Ali SH, Ahmed ES, Mohamed KA: Treatmentseeking behaviour for malaria in children under five years of age: implications for home management in rural areas with high seasonal transmission in Sudan. Malar J 2006, 5:60.

34. Montgomery CM, Mwengee W, Kong'ong'o M, Pool R: 'To help is to educate them': power and pedagogy in the prevention and treatment of malaria in Tanzania. Trop Med Int Health 2006, II:I66I-1669.

35. Muela S, Ribera JM, Tanner M: Fake malaria and hidden parasites-the ambiguity of malaria. Anthropol \& Med 1998, 5:43-6I.

36. Muela SH, Ribera JM, Mushi AK, Tanner M: Medical syncretism with reference to malaria in a Tanzanian community. Soc Sci Med 2002, 55:403-13.

37. Munguti KJ: Community perceptions and treatment seeking for malaria in Baringo district, Kenya: implications for disease control. East Afr Med J 1998, 75:687-91.

38. Muula AS, Chimalizeni $Y$ : Knowledge, attitudes and practices towards malaria among primary school pupils in Ndirande, Blantyre, Malawi. Trop Doct 2004, 34:90-3.

39. Mwenesi H, Harpham T, Snow RW: Child malaria treatment practices among mothers in Kenya. Soc Sci Med 1995, 40:127I-7.

40. Mwenesi HA, Harpham T, Marsh K, Snow RW: Perceptions of symptoms of severe childhood malaria among Mijikenda and Luo residents of coastal Kenya. J Biosoc Sci 1995, 27:235-44.

4I. Nsungwa-Sabiiti J, Kallander K, Nsabagasani X, Namusisi K, Pariyo G, Johansson A, Tomson G, Peterson S: Local fever illness classifications: implications for home management of malaria strategies. Trop Med Int Health 2004, 9: I I9I-9.

42. Nuwaha F: People's perception of malaria in Mbarara, Uganda. Trop Med Int Health 2002, 7:462-470.

43. Nyamongo IK: Health care switching behaviour of malaria patients in a Kenyan rural community. Soc Sci Med 2002, 54:377-86.

44. Oberlander L, Elverdan B: Malaria in the United Republic of Tanzania: cultural considerations and health-seeking behaviour. Bull World Health Organ 2000, 78:1352-7.

45. Okrah J, Traore C, Pale A, Sommerfeld J, Muller O: Community factors associated with malaria prevention by mosquito nets: an exploratory study in rural Burkina Faso. Trop Med Int Health 2002, 7:240-8.

46. Onwujekwe O, Dike N, Uzochukwu B: Issues of measuring and improving the treatment of malaria in sub-Saharan Africa. Trop Doct 2005, 35:224-5.

47. Rashed S, Johnson H, Dongier P, Moreau R, Lee C, Crépeau R, Lambert J, Jefremovas V, Schaffer C: Determinants of the Permethrin
Impregnated Bednets (PIB) in the Republic of Benin: the role of women in the acquisition and utilization of PIBs. Soc Sci Med 1999, 49:993-1005.

48. Stephens C, Masamu ET, Kiama MG, Keto AJ, Kinenekejo M, Ichimor $\mathrm{K}$, Lines J: Knowledge of mosquitos in relation to public and domestic control activities in the cities of Dar es Salaam and Tanga. Bull World Health Organ 1995, 73:97-104.

49. Williams HA, Kachur SP, Nalwamba NC, Hightower A, Simoonga C, Mphande PC: A community perspective on the efficacy of malaria treatment options for children in Lundazi district, Zambia. Trop Med Int Health 1999, 4:64I-52.

50. Winch PJ, Makemba AM, Kamazima SR, Lurie M, Lwihula GK, Premji Z, Minjas JN, Shiff CJ: Local terminology for febrile illnesses in Bagamoyo District, Tanzania and its impact on the design of a community-based malaria control programme. Soc Sci Med 1996, 42:1057-67.

51. Nganda RY, Drakeley C, Reyburn H, Marchant T: Knowledge of malaria influences the use of insecticide treated nets but not intermittent presumptive treatment by pregnant women in Tanzania. Malar J 2004, 3:42.

52. World Health Organization: WHO guidelines for the treatment of malaria 2006 [http://www.who.int/malaria/docs/ TreatmentGuidelines2006.pdf].

53. Meremikwu MM, Oyo-Ita A: Physical methods versus drug placebo or no treatment for managing fever in children. Chochrane Database Syst Rev 2003, 2:CD004264.

\section{Pre-publication history}

The pre-publication history for this paper can be accessed here:

\section{http://www.biomedcentral.com/1472-698X/9/26/pre} pub
Publish with Biomed Central and every scientist can read your work free of charge

"BioMed Central will be the most significant development for disseminating the results of biomedical research in our lifetime. "

Sir Paul Nurse, Cancer Research UK

Your research papers will be:

- available free of charge to the entire biomedical community

- peer reviewed and published immediately upon acceptance

- cited in PubMed and archived on PubMed Central

- yours - you keep the copyright
BioMedcentral 